\title{
Fibrinolysis/Proteolysis Balance in Stable Angina Pectoris in Relation to Angiographic Findings
}

\author{
J. A. Páramo ${ }^{1}$, J. Orbe ${ }^{1}$, J. Fernández \\ ${ }^{1}$ Atherosc lerosis Research Unit, Division of Cardiova sc ular Pathophysiology and Biochemistry, \\ 2University Clinic, School of Medic ine, University of Navarra, Pamplona, Spain
}

Keywords

Fibrinolysis, proteolysis, coronary disease, t-PA

\section{Summary}

The plasma fibrinolytic/proteolytic balance was assessed in 60 stable angina patients who underwent control coronary catheterization and the results were correlated with angiographic findings and control samples $(\mathrm{n}=20)$. The concentrations of t-PA, PAI-1, collagenase (MMP-1), tissue inhibitor of MMP (TIMP-1), plasmin-antiplasmin (PAP) complexes and $\alpha 2$-macroglobulin $(\alpha 2-\mathrm{M})$ were measured in plasma samples. The results showed a significant increase of PAP $(\mathrm{p}<0.001)$ and a reduction of $\alpha 2-\mathrm{M}(\mathrm{p}<0.001)$ in the group of patients when compared to controls, indicating a degree of fibrinolysis/proteolysis activation. There was no correlation between the different parameters analyzed and the extent of angiographically proven atherosclerosis (one or more stenotic vessels), while the t-PA levels were significantly elevated ( $\mathrm{p}<0.03$ ) in patients with coronary stenosis $\geq 75 \%$ or occlusion. We conclude that there is a disturbance of the plasma fibrinolysis/ proteolysis in patients with stable angina not related to the extent of atherosclerosis. The t-PA levels may be a good marker for coronary occlusion in these patients.

\section{Introduction}

The plasminogen (or fibrinolytic) and the metalloproteinase (MMPs) systems have been implicated in the remodeling of extracellular matrix (ECM) during endothelial cell injury (1-3). The plasminogen system is composed of an inactive proenzyme plasminogen that can be converted to plasmin by the plasminogen activators (PA), tissue-type (t-PA), or urokinase-type (u-PA). This system is controlled at the level of PA by specific inhibitors, of which PAI-1 is believed to be physiologically the most important, and at the level of plasmin, mainly by $\alpha 2$-antiplasmin $(\alpha 2-\mathrm{AP})$ and other non-specific inhibitors such as $\alpha 2$-macroglobulin $(\alpha 2-M)(4)$. Due to its fibrin-specificity, t-PA is primarily involved in clot dissolution, whereas u-PA binds a cellular receptor and has been implicated in pericellular proteolysis during cell migration and tissue remodeling during atherosclerosis (1). The MMPs or matrixins also play a pathogenic role in the development of aterosclerosis and plaque rupture (5). This system is controlled by specific tissue inhibitors of MMPs (TIMPs) or by non-specific inhibitors such as $\alpha 2-\mathrm{M}(6-9)$.

Several interactions between the plasminogen/plasmin and MMPs systems suggest that both systems may cooperate in achieving ECM

Correspondence to: Dr. J. A. Páramo, Atherosclerosis Research, Hematology Service, University Clinic of Navarra, P. O. Box 4209, 31080-Pamplona, Spain Tel.: +34 948 296397; Fax: +34 948 296500; E-mail: japaramo@unav.es degradation (10-12). While serial changes in the proteinase systems have been documented in patients with acute coronary syndromes $(13,14)$, no studies have been performed in stable patients in relation to angiographic findings. The aim of this study was to assess the changes in the fibrinolytic/proteolytic balance in a series of stable angina patients and to investigate their relationship to atherosclerosis modifications assessed by coronary catheterization.

\section{Patients and Methods}

\section{Patients}

Sixty consecutive patients (M/F: 49/11, mean age 59 years old) with stable angina pectoris and referred to the cardiology department for control coronary angiography were investigated. None of the patients had a recent (less than a month) myocardial infarction or angioplasty. The presence of the following atherosclerotic risk factors was considered in each patient: hypercholesterolemia (>210 mg/dl), hypertension (>140/90 mmHg), smoking (>10 cigarettes/ day) and non insulin-dependent diabetes mellitus. A coronary angiography was performed using the Judkins tecnique and the severity of coronary atherosclerosis was assessed as no changes or $\geq 75 \%$ stenosis or occlusion in one or more vessels. Intravenous heparin $(75 \mathrm{U} / \mathrm{kg}$ ) was administered prior to the onset of angiography.

In addition, 20 age-matched normocholesterolemic and normotensive subjects (mean age 52 years old, 13 men) without evidence of any systemic disease or infection in the previous month were included as controls. None of the subjects were taking any medication or had any evidence of metabolic disease.

\section{Blood Sampling}

After informed consent, blood samples from patients were drawn at the time of cardiac catheterization. The first $5 \mathrm{ml}$ were discarded and the subsequent $4.5 \mathrm{ml}$ were mixed $(9 / 1, \mathrm{v} / \mathrm{v})$ with trisodium citrate $(0.13 \mathrm{M})$ and centrifuged at $2,500 \times \mathrm{g}$ during $15 \mathrm{~min}$ at $4^{\circ} \mathrm{C}$. Samples of platelet-poor plasma were snap frozen and stored at $-70^{\circ} \mathrm{C}$ until assayed. Venous blood samples were obtained in the group of healthy subjects and served as control samples.

\section{Haemostatic Tests}

- The level of tissue-type plasminogen activator (t-PA) antigen was determined with an ELISA assay (tintElize t-PA from Biopool, Sweden) (15).

- The plasminogen activator inhibitor (PAI-1) activity was measured with an amidolytic method as previously described (16).

- Plasmin-antiplasmin (PAP) complexes were determined by an ELISA method as described by Montes et al (17).

- The plasma concentrations of collagenase (MMP-1) and tissue inhibitor of metalloproteinases (TIMP-1) were determined with commercially available ELISAs (Amersham Pharmacia Biotech, UK).

- $\alpha 2$-Macroglobulin $(\alpha 2-\mathrm{M})$ was determined by a nephelometric assay in a Beckman coulter using the array $\mathrm{TM}_{\mathrm{alpha}}$-macroglobulin kit (Beckman, Ireland). 
Table 1 Baseline clinical characteristics of patients

\begin{tabular}{lcc}
\cline { 2 - 3 } & No occlusion $(\mathrm{n}=13)$ & Stenosis or occlusion $(\mathrm{n}=47)$ \\
\hline Age (years) & $55.6 \pm 9.1$ & $63.1 \pm 4.9$ \\
Sex $(\mathrm{M} / \mathrm{F})$ & $10 / 3$ & $39 / 8$ \\
No risk factors $\#$ & $5(38.5 \%)^{*}$ & $7(14.9 \%)$ \\
One risk factor & $5(38.5 \%)$ & $19(40.4 \%)$ \\
Two or more risk factors & $3(23 \%)$ & $21(44.7 \%)^{*}$ \\
\hline
\end{tabular}

\# The risk factors recorded were hypercholesterolemia, hypertension, smoking and diabetes

$* \mathbf{p}<0.01$

Table 2 Fibrinolysis and proteolysis ${ }^{\#}$ parameters in patients and controls (mean \pm SEM is reported)

\begin{tabular}{|l|c|c|}
\hline \multicolumn{2}{c}{ Patients $(\mathrm{n}=60)$} & Controls $(\mathrm{n}=20)$ \\
\hline t-PA $(\mathrm{ng} / \mathrm{mL})$ & $9.8 \pm 0.7$ & $9.1 \pm 0.8$ \\
\hline PAI-1 (U/mL) & $14.1 \pm 0.9$ & $12.1 \pm 1.9$ \\
\hline PAP $(\mathrm{ng} / \mathrm{ml})$ & $1174.5 \pm 143.5^{*}$ & $340.2 \pm 32.7$ \\
\hline TIMP-1 (ng/mL) & $111.8 \pm 7.3$ & $100.7 \pm 6.2$ \\
\hline$\alpha 2-M(\mathrm{mg} / \mathrm{dL})$ & $137.5 \pm 5.5^{*}$ & $178.8 \pm 5.8$ \\
\hline
\end{tabular}

\# The metalloproteinase (MMP) levels were in patients and controls below the detection limit of the assay

$\mathbf{t}-\mathrm{PA}=$ Tissue-type plasminogen activator; $\mathrm{PAI}-1=$ Plasminogen activator inhibitor

$\mathrm{PAP}=$ Plasmin-Antiplasmin complexes; TIMP-1=Tissue inhibitor of MMP;

$\alpha 2-\mathrm{M}=\alpha 2-\mathrm{Mac}$ oglobulin.

${ }^{*} \mathrm{p}<0.001$ as compared to controls

\begin{tabular}{|l|c|c|}
\hline \multicolumn{2}{c}{ Stenosis or occlusion $(\mathrm{n}=47)$} & No occlusion $(\mathrm{n}=13)$ \\
\hline $\mathrm{t}-\mathrm{PA}(\mathrm{ng} / \mathrm{mL})$ & $10.5 \pm 0.7^{*}$ & $7.5 \pm 0.9$ \\
\hline PAI-1 $(\mathrm{U} / \mathrm{mL})$ & $14.9 \pm 1.0$ & $11.2 \pm 1.9$ \\
\hline PAP $(\mathrm{ng} / \mathrm{ml})$ & $984.1 \pm 143.5$ & $1146.2 \pm 163.8$ \\
\hline TIMP-1 $(\mathrm{ng} / \mathrm{mL})$ & $110.8 \pm 8.3$ & $115.4 \pm 16.1$ \\
\hline$\alpha 2-\mathrm{M}(\mathrm{mg} / \mathrm{dL})$ & $135.6 \pm 6.6$ & $143.2 \pm 10.1$ \\
\hline
\end{tabular}

Table 3 Fibrinolysis and proteolysis parameters in stable angina patients with and without coronary occlusion according angiography (mean \pm SEM is reported)

\section{Biochemical Assays}

The total serum cholesterol, glucose and triglycerides were measured by standard enzymatic methods.

\section{Statistical Analysis}

The results are expressed as mean \pm SEM. Statistical analysis was done using the Wilcoxon and Mann-Whitney tests for mean comparisons of paired and unpaired data respectively. Evaluation of parameters with respect to locus and severity of vascular lesion was performed by repeated measures analysis of variance (ANOVA). Correlation coefficients were calculated with the Spearman rank test. A probability of $\mathrm{p}<0.05$ was considered significant.

\section{Results}

We obtained blood samples from 60 stable angina pectoris patients who underwent coronary angiography, of whom 47 (78.3\%) presented severe coronary stenosis stenosis or occlusion in one or more vessels and $13(21.7 \%)$ showed coronary patency. Table 1 shows the baseline characteristics of patients and the differences in the number of coronary risk factors in those with and without stenosis $(p<0.01)$. The mean levels of the different fibrinolysis and proteolysis parameters analyzed in patients and controls are shown in Table 2. A significant increase of PAP ( $p<0.001)$ and a decrease of $\alpha 2-\mathrm{M}(\mathrm{p}<0.001)$ were observed in the group of patients, without differences in t-PA and PAI-1 levels between groups. In every case, the MMP-1 concentrations were below the detection limit, whereas TIMP-1 levels did not differ significantly between patients and controls.

Results of the different parameters analyzed between patients with and without coronary stenosis or occlusion are shown in Table 3. No differences for the different parameters analyzed could be demonstrated between both groups except for t-PA antigen, which was significantly elevated in patients with occlusion as compared to those with angiographically verified coronary patency $(\mathrm{p}<0.03)$. The PAP levels showed a tendency to be higher in patients without coronary occlusion, although no significant differences were observed. 
The analysis of the different fibrinolysis and proteolysis parameters analyzed in relation to the extent of atherosclerosis (one or more vessels affected) showed no significant differences in relation to the number of vessels damaged (data not shown). Finally, no significant correlations between the parameters analyzed and the metabolic profile could be demonstrated in the patients group.

\section{Disc ussion}

This study demonstrates that in patients with stable angina and no antecedents of myocardial infarction, there is a disturbance in the plasma fibrinolysis/proteolysis state not related to the extent of atherosclerosis as assessed by coronary catheterization.

Whereas a significant increase of PAP and a decrease of $\alpha 2-\mathrm{M}$ was observed in patients when compared to controls, suggesting a degree of fibrinolysis/proteolysis activation, no differences were observed in the levels of TIMP-1 and no circulating MMP-1 could be detected. Increased plasma PAP has been found in different clinical conditions related to thrombosis including myocardial infarction (18). Whether PAP may also be a marker for local degradation of ECM in atheroma leading to plaque destabilization and rupture needs to be properly assessed. With regard to $\alpha 2-\mathrm{M}$, some reports have indicated that atherosclerotic patients exhibit changes in the levels of this serine protease inhibitor, which might act as a sensor for local increases in proteolytic activity $(19,20)$. It has been suggested that the regulation of ECM degradation may not only be promoted by activated proteinases but also accelerated by decreased levels of serpins, such as $\alpha 2-\mathrm{M}(21)$.

Interestingly, the observed changes in the parameters analyzed were not related to the extent of angiographically proven atherosclerotic lesions (one or more vessels affected), suggesting that early anomalies in the fibrinoytic/proteolytic balance can be detected in plasma before the development of stablished coronary atherosclerosis. This was also true in patients with proven coronary stenosis or occlusion, except for the t-PA antigen levels being significantly increased in these patients when compared to those without occlusion, indicating that t-PA may be a good marker for arterial thrombosis (22-24). The observed tendency to high PAP in the small subgroup of patients without occlusion would also suggest that a higher fibrinolytic activity may favor the absence of occlusion.

We conclude that there is an impairment of the fibrinolysis/proteolysis balance in the plasma of patients with stable angina pectoris not related to the extent of coronary atherosclerosis. The lack of differences in the systemic levels of MMP/TIMP-1 does not rule out the possibility that local changes in vascular proteolysis might contribute to the atherosclerotic process in the more severe patients (25-28). Finally, our results underscore the importance of t-PA antigen as a marker for severity in stable angina pectoris, most likely reflecting endothelial dysfunction.

\section{References}

1. Collen D. The plasminogen (fibrinolytic) system. Thromb Haemost 1999; 82: $259-70$.

2. Nagase H, Woessner JF. Matrix metalloproteinases. J Biol Chem 1999; 274: 21491-4.

3. Galis ZS. Metalloproteases in remodelling of vascular extracellular matrix. Fibrinolysis 1999; 13: 54-63.

4. Borth W. a2-Macroglobulin. A multifunctional binding and targeting protein with possible roles in immunity and autoimmunity. Ann N Y Acad Sci, USA 1999; 878: 267-72.
5. Galis ZS, Sukhova GK, Lark MW Libby P. Increased expression of matrix metalloproteinases and matrix-degrading activity in vulnerable regions of human atherosclerotic plaques. J Clin Invest 1994; 94: 2493-503.

6. Barret AJ, Starkey PM. The interaction of $\alpha 2$-macroglobulin with proteinases: characteristics and specificity of the reaction, and a hypothesis concerning its molecular mechanism. Biochem J 1973;133: 709-24.

7. Denis LJ, Verweij J. Matrix metalloproteinase inhibitors: present achievements and future prospects. Investigational New Drugs 1997; 15: 175-85.

8. Fabunmi RP, Sukhova GK, Sugiyama S, Libby P. Expression of tissue inhibitor of metalloproteinases-3 in human atheroma and regulation in esion associated cells. A potential protective mechanism in plaque stability. Circ Res 1998; 83: 270-8.

9. Prescott MF, Sawyer WK, von Linden-Reed J, Jeune M, Chou M, Caplan SL, Jeng AY. Effect of matrix metalloproteinase inhibition on progression of atherosclerosis and aneurysm in LDL receptor-deficient mice overexpressing MMP-3, MMP-12, and MMP 13 and on restenosis in rats after balloon injury. Ann NY Acad Sci 1999; 878: 179-90.

10. Carmeliet P, Moons L, Lijnen HR, Baes M, Lemaitre V, Tipping P, Drew A, Eeckout Y, Shapiro S, Lupu F, Collen D. Urokinase-generated plasmin is a candidate activator of matrix metalloproteinases during atherosclerotic aneurysm formation. Nature Gen 1997; 17: 439-44.

11. Lijnen HG, Van Hoef BV, Lupu F, Moons L, Carmeliet P, Collen D. Function of the plasminogen/plasmin and matrix metalloproteinase systems after vascular injury in mice with targeted inactivation of fibrinolytic system genes. Arterioscler Thromb Vasc Biol 1998; 18: 1035-45.

12. Lijnen HR. Molecular interactions between the plasminogen/plasmin and matrix metalloproteinase systems. Fibrinol Proteol 2000; 14: 175-81.

13. Páramo JA, Panizo C, Montes R, Orbe J, Alegría E, Martínez-Caro D, Dooijewaard G. Markers of fibrinolytic potency and clotting activation in stable angina pectoris: role of urokinase, assessment of atrioventricular differences and correlation with coronary patency. Fibrinol Proteol 1999; 13: $133-8$.

14. Kai H, Ikeda H, Yasukawa H, Saki Y, Kuwahara F, Ueno T, Sugi K, Imaizumi T. Peripheral blood levels of matrix metalloproteinases- 2 and- 9 are elevated in patients with acute coronary syndromes. J Am Coll Cardiol 1998; 32: 368-72.

15. Korninger C, Speizer W, Wojta J, Binder RR. Sandwich ELISA for t-PA antigen employing a monoclonal antibody. Thromb Res 1983; 31: 427-36.

16. Páramo JA, Alfaro MJ, Rocha E. Postoperative changes in the plasmatic levels of tissue-type plasminogen activator and its fast-acting inhibitor: relationship to deep venous thrombosis and influence of prophylaxis. Thromb Haemost 1985; 54: 713-6.

17. Montes R, Páramo JA, Anglés-Cano E, Rocha E. Development and clinical application of a new ELISA assay to deterfmine plasmin- $\alpha 2$-Antiplasmin complexes in plasma. Br J Haematol 1996; 92: 979-85.

18. López Y, Paloma MJ, Rifón J, Cuesta B, Páramo JA. Measurement of prethrombotic markers in the assessment of acquired hypercoagulable states. Thromb Res 1999; 93: 71-8.

19. Mohacsi AT, Fulop B, Kozlovsk y M, Hanck M, Kiss I, Leovey A. Sera and leukocyte elastase-type protease and antiprotease activity in healthy and atherosclerotic subjects of various ages. J Gerontol 1992; 47: 154-8.

20. Chu CT, Howard GC, Pizzo SV. $\alpha 2$-Macroglobulin: a sensor for proteolysis. Ann NY Acad Sci, USA 1999; 878: 291-307.

21. Oleksyszyn J, Augustine AJ. Plasminogen modulation of IL-1-stimulated degradation in bovine and human articular cartilage explants. The role of the endogenous inhibitors, PAI-1, aspha-2-antiplasmin, alpha-1-PI, alpha-2-macroglobulin and TIMP. Inflammation Res 1996; 45: 464-72.

22. Thompson SG, Kienast J, Pyke SDM, Haverkate F, va de Loo JLW. Hemostatic factors and the risk of myocardial infarction or sudden death in patients with angina pectoris. N Engl J Med 1995; 332: 635-41.

23. Ridker PM, Vaughan DE, Stampfer MJ, Manson JE, Hennekens CH. Endogenous tissue-type plasminogen activator and risk of myocardial infarction. Lancet 1993; 341: 1165-8. 
24. Ridker PM, Hennekens CM, Stampfer MJ, Manson JE, Vaughan DE. Prospective study of endogenous tissue plasminogen activator and risk of stroke. Lancet 1994; 343: 940-3.

25. Brown DL, Hibbs MS, Kearney M, Loushin C, Isner JM. Identification of 92-kd gelatinase in human coronary atherosclerotic lesions. Association of active enzyme synthesis with unstable angina. Circulation 1995; 92: $1565-9$.

26. Shah PK, Falk E, Badimon JJ, Fernández-Ortiz AF, Mailhac A, VillarrealLevy G, et al. Human monocyte-derived macrophages induce collagen breakdown in fibrous caps of atherosclerotic plaques. Potential role of matrix degrading metalloproteinases and implications for plaque rupture. Circulation 1995; 92: 1565-9.
27. Galis ZS, Sukhova GK, Libby P. Microscopic localization of active proteases by in situ zymography: detection of metalloproteinase activity in vascular tissue. FASEB J 1995; 9: 974-80.

28. Marathe S, Kuriakose G, Williams KJ, Tabas I. Sphingomyelinase, an enzyme implicated in atherogenesis, is present in atherosclerotic lesions and binds to specific components of the subendothelial extracellular matrix. Arterioscler Thromb Vasc Biol 1999; 19: 2648-58.

Received July 18, 2000 Accepted after resubmission February 28, 2001

\section{Ordering has never been so easy:}

\section{http:// ww w.schattauer.com}

